\title{
Situated Intervention: Response to Comments
}

\author{
Teun Zuiderent-Jerak \\ Department of Thematic Studies, Technology and Social Change, Linköping university, Sweden / \\ teun.zuiderent-jerak@liu.se
}

\begin{abstract}
"So why are you wearing a tie today?"
"Well, I'Il have to leave a little earlier. I'm acting as opponent again this afternoon in Leiden. And yourself? Off to another guideline meeting in Nice?"
\end{abstract}

Five people are taking their seats at a small meeting table in the office of an oncology professor at a large Dutch university hospital. Two of them are professors of oncology and haematology. The other three are made to listen to this exchange of importances. Two of them are specialised oncology nurses. The last one is me. None of us are wearing ties.

This group is meeting to discuss the delegation of some of the oncologists' tasks to these specialised nurses. It seems like everyone in the room is sceptical. The doctors are sceptical about the skills the nurses bring to such nurse-led clinics. "Before we start, we should perhaps still train some conversation-techniques with you?", the oncologist suggests.

“Talking about conversation skills!", one of the nurses snaps, as soon as the doctors have left us to go to their important elsewheres. "That bragging about their ties shows how great they are at that! 'Conversation-skills'... That is what our whole education was about!" They are a little more than sceptical about the understanding the doctors have of their work, and of how they will be able to cooperate in such clinics.

And me? Well, I'm sceptical about the chances of success of delegating tasks within a setting with such fraught politics of professions. But I've been reading Suchman, Star, and so many other of my heroes of feminist STS scholarship dealing with the politics of workplaces (Suchman, 1995, 2000; Star, 1991; Star \& Bowker, 1995; Star \& Strauss, 1999). And conceptualising what I'm encountering here as 'making skilful invisible work visible' is surely more interesting than sociology of professions' analyses that reify rather than reconfigure power relations. So, I guess we'll just keep going with the experiment of setting up nurse-led clinics, and meanwhile enhance the legitimacy of the nurses by organising professionalization sessions on the ward for nurses, to show to the doctors that they do really have the skills to take over some of their tasks.

During the first of those training sessions on cutting edge developments in chemotherapy, something puzzling happens. The nurses start asking so many questions about the regular chemotherapies they administer on a daily basis, that the instructor has to change his training to focus only on basics aspects of their everyday work. "You know," the nursing manager afterwards tries to justify, "this is just part of how things are around here. We are an outpatient clinic and day care treatment centre, and most of the nurses don't work here because of their interest in oncology, but because they never have to work nights or weekends. They just want to be on time to pick up the kids from school."

So what was I to make of this?! I love that scholarship on skilful but marginalised invisible work! The work that shows that the skilful work of for 
example nurses often is invisible, though not in the sense that it cannot be observed, but, as Star and Strauss (1999: 20) wrote, "if one looked, one could literally see the work being done-but the taken-for-granted status means that it is functionally invisible." How to deal with the fact that, now that I was trying to undo the taken-for-granted status of nursing work, this brought to the fore the unskilful invisible work that was going on at the ward? What could this surprise mean for what I was to do next in this improvement project, for scholarly understandings of invisible work, and for my normative attachments to making visible marginalised work practices?

Struggling with such questions is what made me write Situated Intervention. How can the direct involvement of STS scholars in the practices they study lead to the production of interesting STS knowledge and normativity? What is there to gain from intervening in practices to learn from such experiments that tell us something about the field and about ourselves, both in terms of our scholarly as well as our personal attachments?

The generous and inventive readings of the book presented here raise some serious questions. Here I take those questions as invitations for further situating the book as itself an entity to think with and through within ongoing concerns within STS. As far as I can see, the puzzles raised relate to five topic areas: to what extent are the situated intervention experiments encountered here highly specific, what are the losses of contrasting situated intervention with other dearly held notions such as participation, how to solidify an emergent approach to intervention, how does situated intervention relate to the becoming of the person/scholar, and what about the relationships between sociology and STS. These are five areas that each in and of themselves would require extensive comments, so my thoughts on them here are merely the start of what I hope are longer conversations.

\section{The specific of these situated intervention experiments}

Both commentaries raise questions about what is specific about the experiments explored in the book. The senior manager, Downey, wonders how such fingerpost experiments in his clinic relate to scientific experiments in the natural sciences, especially in relation to their normative complexity. I would agree that one of the reasons why I have a particular interest in studying health care practices, is that their normative complexity is nearly impossible to avoid. So there are indeed reasons for exploring situated intervention experiments in this particular empirical domain, which of course is not to say that scientific experiments are devoid of such normative complexities. The work of scholars like Sarah Kember (2003) is one of the inspirations for the book, and her work is focussed on finding frictions within practices of scientific experimentation. So although health care surely is not indispensable for the argument of the book, exploring the production of new knowledge and new normativities through experiments in health care could be seen in line with the advice given by Howard Becker (1967: 246), and that I draw upon in the book, to study "impartially," meaning that scholarship should be applied so that "a belief to which we are especially sympathetic could be proved untrue." If putting our beliefs at risk is central to situated intervention, situations like the one I introduced above are not the problems but the product of situated intervention. Normative complexities are not merely encountered; they are produced. This makes me hopeful for the ability of situated intervention experiments to produce normative complexities in a wide range of empirical domains.

\section{Opening up problem spaces: What about participation}

Given that the book is about situating interventions in sociologically unpacked and produced normative complexities, what are our repertoires for doing so? And more specifically, ask Marres, Mesman and Winthereik, what about the important repertoire of participation? Isn't participation one of our main resources for opening up a space 'in between' whatever binary opposition we encounter, because of its ability to connect relative strangers? My reply to that would, in common parlance, have to be: let's see. More in line with the argument of the book I would say: let's try. Although participation may well be crucial for articulating frictions within certain practices, this is not necessarily so. I was alerted to this by the 
predominance of calls for 'patient participation' as part of health care quality improvement and for the development of patient-centered care. And although I am obviously sympathetic to the idea of participation, I was taught quite a lesson about my sympathies by a mentally disabled resident of a care facility that was part of a national improvement program for long-term care. In the book I describe how she gave a presentation on the client board that she chairs and that is set up as a Trust, separate but in a loose liaison with the care institution in which she lives. Supported by an attendant employed by the Trust, she explained how the previous client board of the care institution had been absolutely unworkable for clients. When they were invited to attend a meeting, in preparation they had to work their way through piles of documents that had not been written for them and were hard to understand. In their own Trust, the clients set their own agenda for which they may or may not take suggestions by the board into account. The Trust organizes thematic meetings with no more than one topic on the agenda. The members prepare for the meeting by making a short movie about the issue they want to discuss. After the discussion, they come with recommendations to the board. In her presentation, the client problematised the notion of participation: "We are unique: in other places you are allowed to 'participate."' On the last word, she pulled a disgusted face, drawing quite some laughter from the audience. The laughter came from the stunning clarity by which a mentally disabled client could problematize a notion that was held so dearly in the improvement program. So although participation may in some instances be a crucial aspect of situated intervention, I like to follow a second bit of advice I take from Becker. Especially towards dearly held notions like participation, scholars may want to "avoid sentimentality," meaning that we should not shun finding out "what is going on, if to know would be to violate some sympathy" (Becker, 1967: 246). This also means that the question whether participation is a helpful notion is highly dependent upon the issue at stake. So in attempting to empiricise concepts like participation, the issues get more of the credit they deserve, as Marres $(2007,2012)$ has pointed out so well.

\section{Solidifying emergence}

If theoretical STS notions, scholarly normativity, and interventions all are in flux, and crucially so, how then to solidify this process of situatedness and flexibility? If situated intervention is about creating something new that was already there but that could only be brought into being by challenging common understandings of, say, health care markets, standardised care pathways or patient safety, how then to consolidate the adaptive strength? It is unsurprising that Marres, Mesman and Winthereik raise this question, especially given Mesman's (2015) interest in 'exnovation', that is making visible and highlighting competencies and resources that have been "overlooked or forgotten". They thereby focus on precisely one of the toughest challenges of situated intervention. In a sense, I think of this question as the puzzle of intervening less. Although I am largely suspicious of more-less renderings of scholarly debates, to counter a concern I have about this book being read as a call for 'more intervention', I would like to stress that at times the most important interventions where those that were less specific than expected by actors in the field. In a national improvement project focussing on the redesign of the care trajectories for oncology and elective surgery patients, I asked teams to draw intentionally sketchy flow charts. This was particularly challenging since flow charts are often part of the development and introduction of integrated care pathways, and the quality managers working in the program had learned to map and describe each step in the care process, redesign it, and implement the redesigned process - exactly the kind of separation of innovation and implementation that I fervently tried to avoid. Such a pragmatic and sociologically inspired way of doing standardization, that drew upon a processual understanding of pathwaying, therefore caused quite some frustration among quality managers trained in a more rigid approach. It actually led to complaints about the program being insufficiently helpful in providing access to best practices, which we countered by providing a map of which hospitals were working on which topics, including the phone numbers of the contact persons there. With this we tried to speak to their concerns about learning more from 
each other, without specifying which practices were 'best'. This may now however sound easier than it was. It was actually very hard to keep standards sketchy, and to highlight the process of standardisation rather than the production and implementation of standards. And where this was hard in relation to standards within health care practices, it was equally hard for normative concerns in scholarly debates. There also, there were repeated calls for specifying 'Archimedean ethical points' which, I was told, would be needed to avoid doing 'just management' and reducing scholarship to 'normative empiricism'. Trying, with Canguilhem, to define the capacity for normativity as the variability in response (Canguilhem, 1994; Brown \& Stenner, 2009: 160) was therefore equally challenging as keeping open and resisting the fear of inaction (Jerak-Zuiderent, 2015) in the face of calls for products of health care improvement. In this sense, the hardest part about exnovation seems to be not just the shift of the STS scholar to focussing on letting something new emerge that is already there, but to keep doing so in the light of repeated calls for external answers - both in terms of health care improvement and scholarly normativity.

\section{Emerging scholars}

To what extent are STS scholars the product of situated intervention? If scholarly attachments are put at risk, what does this do to the researcher beholding such attachments, especially when the practices encountered need to be taken almost more seriously than the scholarly concerns? These are important questions that Downey raises. I would say that needing to take the realities encountered and understood by the field seriously has, in scholarly terms, often been more of a gain than a loss. In the case of delegating tasks to oncology nurses, I surely tried to fight the understanding of the site that the doctors displayed by not trusting the skills of the nurses. And if I had done a more traditional ethnographic study of health care work, I could have quite easily turned my empirics into a story about invisible work resulting in problematic workplace design. But when trying to develop the nurse-led clinic, it simply proved too hard to maintain my critique of the doctors' understanding. And these are the kinds of situations that made me realize that, paraphrasing Suchman and Trigg's (1991) concept of 'artful integration', situated intervention should be carried out with the aim of achieving 'artful contamination'. Where contamination stops STS from getting locked into pre-given problem spaces, "anti-bodies" have to be artfully cultivated by being part of STS conversations. And indeed, this means that distinctions between the field, the scholar, and the person become profoundly problematised. As a result, I have come to appreciate the value of standardization that is situated in specified understandings of a setting and thereby have come to love standards in a way I hadn't imagined, while becoming increasingly sceptical about any normative standards in the form of scholarly attachments that pretend not to need such situatedness because of their obvious superiority. This doesn't mean that I am no longer attached to notions like 'invisible work', but that I have become pertinently aware of the risk of failing to specify why, here, for whom, and at what costs - even in the case of seemingly superior notions.

\section{Sociology and STS}

The last question raised by Downey raises a huge topic, while I will only be able to provide a very short response here. What about the difference between sociology and STS? What would happen if the subtitle referred to STS experiments? In honesty, the request to open up the focus of the debate from STS to a wider audience came from the publisher and the reviewers. At first I was sceptical about this. Having a disciplinary training in the interdiscipline of STS, I saw little value in and felt fairly insecure about engaging with wider sociological debates. But I must say that the journey into sociological debates offered quite some pleasant surprises. It was for example fascinating to find that debates about taking sides in urban sociology contained nuanced positions that had a lot to offer to debates on captivity in STS. Being of a generation that, ironically speaking, at times seems to consider STS to be a field that was 'discovered' in Paris in 1987, I started out adhering to reviewers' demands and ended up learning much about the inspiration the pre-histories of STS can offer. For example, Becker's advice to 
acknowledge attachments while avoiding sentimentality about them turned out to be a crucial element of situated intervention. When I did not find the expected 'skilful invisible work' among oncology nurses, as I described at the start of this response, I did not simply give up on dearly held attachments to this notion. We rather started out with a dedicated nurse-led clinic that aimed more modestly at the improvement of general communication with patients about their treatment. This allowed at least for a much-needed collaborative connection between oncologists and nurses, as now they would have to begin working together and discussing their findings during consults. And it equally allowed me to be attached to a notion like invisible work, but in a somewhat more detached way. My hope is that exploring the relevance of earlier sociological debates for current scholarship modestly contributes to resisting the hardening of disciplinary boundaries rather than to territorial claims about STS mainly being part of one or the other of it's related disciplines.

\section{References}

Becker HS (1967) Whose Side Are We On? Social Problems 14(3): 239-247.

Brown SD \& Stenner P (2009) Psychology Without Foundations; History, Philosophy and Psychosocial Theory. London: SAGE publications.

Canguilhem G (1994) Normality and Normativity. In: Delaporte F (ed) A vital rationalist: selected writings from Georges Canguilhem. New York: Zone.

Jerak-Zuiderent S (2015) 'Keeping Open' by Re-imagining Fears and Laughter. The Sociological Review 63(4): 897-921.

Kember S (2003) Cyberfeminism and Artificial Life. London \& New York: Routledge.

Marres N (2007) The Issues Deserve More Credit: Pragmatist Contributions to the Study of Public Involvement in Controversy. Social Studies of Science 37(5): 759-780.

Marres N (2012) Material Participation; Technology, the Envirnoment and Everyday Publics. London: Palgrave Macmillan.

Mesman J (2015) Boundary-spanning Engagements on a Neonatal Ward: A Collaborative Entanglement between Clinicians and Researchers. In: Penders B, Vermeulen N, \& Parker J (eds) Collaboration across Health Research and Care. Aldershot: Ashgate Publishing Ltd, 171-194.

Star SL (1991) Invisible work and silenced dialogues in knowledge representation. In: Eriksson IV, Kitchenham BA, \& Tijdens K (eds) Women, Work and Computerization. Amsterdam: Elsevier, 81-92.

Star SL \& Bowker GC (1995) Representations of work: Work and infrastructure. Communications of the ACM 38(9).

Star SL \& Strauss A (1999) Layers of Silence, Arenas of Voice; The ecology of visible and invisible work. Computer Supported Cooperative Work 8(1-2): 9-30.

Suchman L (1995) Representations of work; Making work visible. Communications of the ACM 38(9): 56-64.

Suchman L (2000) Making a case; 'knowledge' and 'routine' work in knowledge production. In: Luff P, Hindmarsh J, \& Heath C (eds) Workplace studies: Recovering work practice and informing system design. Cambridge \& New York: Cambridge University Press.

Suchman L \& Trigg R (1991) Understanding practice: video as a medium for reflection and design. In: Greenbaum J \& Kyng M (eds) Design at work: cooperative design of computer systems. Mahwah, NJ: Lawrence Erlbaum Associates, Inc, 65-90. 